\title{
Diagnostic Accuracy of Sonographic Septations in Tuberculous and Malignant Pleural Effusions
}

\author{
Abdul Rasheed Qureshi ${ }^{1}$, Muhammad Irfan ${ }^{1}$, Zeeshan Ashraf ${ }^{2}$ \\ ${ }^{1}$ Assistant Professor, Gulab Devi Post Graduate Medical Institute Lahore, Pakistan \\ ${ }^{2}$ Lecturer, Department of Statistics, Gulab Devi Educational Complex, Lahore-Pakistan
}

\begin{abstract}
Background: Discrimination between tuberculous (TB) and malignant pleural effusions is a real practical challenge because both exist as exudative lymphocytic type. Transthoracic ultrasonography not only identifies and quantifies pleural effusion but also displays sonographic septations, which are frequently seen in TB pleural effusions and can help in differentiation between tuberculosis and malignancy successfully, without any invasive procedure. We designed this study to determine the diagnostic usefulness of these septations for tuberculous and malignant pleural effusions.

Material and Methods: This prospective study was conducted in the OPD of Gulab Devi Chest Hospital Lahore, Pakistan, a 1500 bedded tertiary care hospital, from November 2016 to February 2018. Total of 339 consecutive cases, aged 14-83 years with radiological evidence of pleural effusion were included in the study. After detailed history, thorough physical examination, radiological, haematological and biochemical findings were recorded. Pleural fluid macroscopic, cytological, microbiologic and biochemical analysis results were also recorded. Ultrasonography was done, septated and non-septated pleural effusions identified and findings were noted. SPSS-16 was used for statistical evaluation. Fisher Exact test was utilized for comparison between TB and malignant cases with $P$-value $<0.05$ taken as significant. Sensitivity, specificity, positive predictive value (PPV), negative predictive value (NPV), diagnostic accuracy and positive likelihood ratio were calculated.

Results: Out of total 339 cases, $49(14.45 \%)$ were malignant and 290 (85.55\%) were non-malignant. In the malignant group, only 03 cases (6.12\%) showed sonographic septations. In the non-malignant group, 259/290 (89.31\%) cases showed tuberculous etiology and 187/259 (72.20\%) of these cases displayed sonographic septations. By considering septations as predictor of TB, statistical analysis revealed a sensitivity of $79.23 \%$, specificity of $92.85 \%$, PPV of $98.42 \%$, NPV of $44.31 \%$ and diagnostic accuracy of $81.29 \%$, respectively.

Conclusions: Sonographic septations can be a valuable predictor of tuberculosis, in a population with high prevalence of the disease. We found it to be a useful feature in differentiating between a malignant and tuberculous etiology, in exudative lymphocytic pleural effusions. It can be used with confidence in patients who are unfit for interventional procedures.
\end{abstract}

Key words: Pleural effusion, Sonographic septations, Transthoracic ultrasonography, Tuberculosis

Authors' Contribution:
${ }^{1-3}$ Conception; Literature research; Muhammad Irfan
manuscript design and drafting; Critical Email: irfan16d2@gmail.com
analysis and manuscript review; Data
analysis; Manuscript Editing.
Cite this article. Qureshi AR, Irfan M, Ashraf Z. Diagnostic Accuracy of Sonographic
Septations in Tuberculous and Malignant Pleural Effusions. J Islamabad Med Dental
Coll.2020; 9(2): 95-102. Doi: 10.35787/jimdc.v9i2.339

Article info:

Received: May 2, 2019

Accepted: June 24, 2020

Funding Source: Nil

Conflict of Interest: Nil 


\section{Introduction}

A pleural effusion (PE) is always abnormal and indicates the presence of an underlying disease. Many infective, neoplastic, inflammatory, metabolic or connective tissue disorders produce pleural effusions. It can be an exudate or transudate depending upon the protein content of the pleural fluid (PF). According to the Global Tuberculosis (TB) report by WHO, TB is endemic in Pakistan, which occupies the fifth position among the high burden countries. ${ }^{1}$ The incidence of TB is $497 / 100,000$ in Pakistan. TB is usually considered the sole cause of an exudative lymphocytic pleural effusion until proven by further work up. According to literature, TB is the most common cause of exudative pleural effusion. ${ }^{2}$ Malignancy and acute infections are also significant contributors. ${ }^{3}$ The Gold Standard for TB diagnosis is capturing acidfast bacilli (AFB) in pleural fluid, but the yield is less than $20 \% .{ }^{4,5}$ About $40-70 \%$ cases can be diagnosed by an invasive procedure like pleural biopsy followed by histopathology ${ }^{6-8}$ In spite of utilizing all these tools, $10-20 \%$ cases still remain undiagnosed. ${ }^{9}$ Similarly negative results on AFB smear, culture and histopathology reports do not rule-out TB.

The chest ultrasonography has been gaining popularity for the evaluation and management of lung cancer, consolidations, mediastinal tumors, and pleural diseases during the last decade. ${ }^{10,11}$ It has emerged as an excellent imaging tool for assessing the quantity and nature of pleural effusions. Sonographic septations are frequently present in exudates and very commonly found in tubercular pleural effusions. ${ }^{12}$ Current literature reports that tuberculous pleural effusions and empyema commonly have complex septated sonographic appearances. ${ }^{13-15}$

Pyogenic effusions (empyema and parapneumonic $\mathrm{PE}$ ) can be isolated by typical clinicopathological findings but the discrimination between TB and malignancy still remains a practical challenge, because both exist as exudative-lymphocytic type of PE. The differentiation between tuberculosis and malignancy is made by pleural fluid cytology, adenosine deaminase levels and pleural biopsy. ${ }^{16,17}$ Pleuroscopic biopsy is the standard widely-used technique, but requires special equipment and expertise. ${ }^{18}$ It has its own complications and lacks cost-effectiveness. ${ }^{19}$ In this scenario, there is a need for a safe, readily available and cost-effective tool capable of discriminating TB from malignancy. This study was designed with the primary objective of evaluating the diagnostic usefulness of sonographic septations in predicting tuberculosis. In order to achieve this objective, we first diagnosed pleural effusions on the basis of pleural fluid analysis and laboratory investigations, then identified the sonographic patterns in different types of PEs and finally compared the usefulness/efficacy of sonographic septations in differentiating between TB and malignant PE.

\section{Material and Methods}

This prospective study was conducted at Pulmonology OPD of Gulab Devi Teaching Hospital, Lahore Pakistan (a 1500 bed tertiary care hospital). Ethical approval was obtained from the IRB of the hospital (IRB No. Admin/GDEC/18-549) prior to the commencement of the study. Informed consent was taken from all the patients enrolled in the study. Sample size was calculated using the OpenEpi sample size formula for cross-sectional studies $\left[\left(Z_{1-a / 2}\right)^{2} \times \quad P(1-P) / d^{2}\right]$. Total of 339 consecutive patients, reporting from November 2016 to February 2018 (15-months period) were recruited. Patients with undiagnosed pleural effusions (on laboratory investigations and ultrasound), aged 14-83 years and willing for pleural aspiration/biopsy were included. The 
exclusion criteria included minimal PE, pleural effusions with diagnosed etiology, previous pleural interventions and any contraindication to pleural aspiration.

The diagnostic tools included chest $x$-ray posteroanterior (PA) and lateral views, and ultrasound examination (Toshiba, Japan) with 3.55.5 $\mathrm{MHz}$ convex probes. After a thorough history and physical examination, patients were evaluated with grey scale ultrasonography machine (Toshiba, Japan) using 3.5-5.5 MHz convex probes. Anterior, posterior and lateral scans were obtained in sitting and supine positions. Both hemithoraces were scanned systematically. Pleural effusions, septations, loculations and pleural thickenings were diagnosed. Four main sonographic patterns were recognized: 1. Anechoic pattern having no echoes inside the effusion (simple effusion), 2. Complex septated pattern with fibrous bands running inside the complex effusion, 3. Complex non-septated pattern with effusion without any septation, 4. Homogenous echogenic pattern with effusion consisting of homogenous bright echoes.

Ultrasound-guided pleural fluid aspiration was done and sent for biochemistry, cytology, AFB smear, culture and sensitivity $(C / S)$ and adenosine deaminase (ADA) levels. CBC, ESR, serum proteins, liver function tests (LFTs) and renal function tests (RFTs) were performed. Pleural fluid analysis results including macroscopic findings, cytological, microbiological and biochemical analysis were recorded. Exudates and transudates were classified by Light's criteria. ${ }^{20}$ Exudates were further subclassified into neutrophilic and lymphocytic by differential leukocyte count (DLC). Para-pneumonic effusions and empyema were diagnosed by typical short history, peripheral leukocytosis, neutrophilic exudate, homogenous echogenic pleural effusion, Gram staining and $\mathrm{C} / \mathrm{S}$ results.
Tuberculosis was diagnosed by history, pyrexia of unknown origin (PUO), history of contact, lymphocytic exudates, caseating granulomas and by capturing AFB. Pleural fluid (PF) ADA level with a cut-off value of $40 \mathrm{IU} / \mathrm{L}$ was used for diagnosis of TB. Anti-TB treatment initiated according to DOTs protocol and response to treatment was considered for final diagnosis. Patients were followed up for six months at least. All observations were recorded in a proforma. Findings were tabulated, sonography patterns were compared with the final clinical diagnosis and statistical analysis was done.

SPSS-16 software package was used for statistical evaluation. Quantitative data was expressed as means with standard deviation and categorical variables were presented as percentages. Fisher Exact test was utilized for comparison between TB and malignant cases. $P$-value $<0.05$ was considered significant. Patients with disease and also having septations were considered true positive (TP), cases with disease but without septations were false negative (FN), cases without disease but with septations were false positive (FP) and patients without any disease and with no septation were defined as true negative (TN). Sensitivity, specificity, PPV, NPV, diagnostic accuracy and positive likelihood ratio were calculated.

\section{Results}

Total 339 cases were enrolled with 233 (68.73\%) male and 106 (31.26\%) female patients, respectively (male-to-female ratio of 2.2:1.2). About 339 (62.24\%) pleural effusions were on the right side while 128 (37.75\%) were on the left side. The mean age of the patients was $48.5 \pm 21.6$ years (age range $14-83$ years). The mean age for tuberculous and pyogenic effusion was 28 years while for malignant group it was 41 years. Fortynine cases (14.45\%) were found with a malignant etiology. Of the non-malignant ( $n=290 ; 85.55 \%)$ 
cases, 259/290 (89.31\%) had tuberculous etiology, while $31 / 290$ cases $(11.96 \%)$ had a pyogenic cause (parapneumonic PE and empyema). Regarding clinical presentation of the patients, 282 (83.18\%) presented with chest pain, $264(77.87 \%)$ with cough, 247 (72.86\%) with fever, 210 (61.94\%) with dyspnea, 200 (58.99\%) with expectoration and 198 (58.4\%) with loss of appetite, respectively. About $48(14.15 \%)$ gave history of previous contact with TB patients, 36 (10.61\%) cases had hemoptysis, 44 (12.97\%) clubbing and $37(10.91 \%)$ cases were found with known diabetes mellitus.

\begin{tabular}{|c|c|c|c|c|c|c|c|c|c|c|c|}
\hline \multirow[b]{2}{*}{$\begin{array}{l}S \\
\text { No }\end{array}$} & \multirow[b]{2}{*}{$\begin{array}{l}\text { Diagnosis } \\
\text { of PE } \\
(n=339)\end{array}$} & \multicolumn{6}{|c|}{$\begin{array}{l}\text { Pleural Fluid Analysis } \\
\text { n (\%) }\end{array}$} & \multicolumn{4}{|c|}{ Mean Concentrations } \\
\hline & & $\begin{array}{l}\text { Clot } \\
+ \text { tve }\end{array}$ & $\begin{array}{l}\text { Mean } \\
\text { Protein } \\
\text { gm/dl }\end{array}$ & AFB & $\begin{array}{l}\text { Pyogenic } \\
\text { Culture }\end{array}$ & $\begin{array}{l}\text { Infl Cells } \\
\text { (Poly/ } \\
\text { Lymph) }\end{array}$ & $\begin{array}{l}\text { Cancer } \\
\text { Cells }\end{array}$ & $\begin{array}{l}\text { Serum } \\
\text { Protein } \\
\text { (gm/dl) }\end{array}$ & $\begin{array}{c}\text { ESR } \\
\left(\mathrm{mm} / 1^{\mathrm{st}}\right. \\
\mathrm{hr})\end{array}$ & $\begin{array}{l}\mathrm{TLC} \\
/ \mathrm{mm}^{3}\end{array}$ & $\begin{array}{c}\mathrm{Hb} \\
(\mathrm{gm} \%)\end{array}$ \\
\hline 1. & $\begin{array}{c}{ }^{*} \mathrm{~TB} \\
(\mathrm{n}=259)\end{array}$ & $\begin{array}{l}251 \\
(97)\end{array}$ & 5.3 & 0.00 & 0.00 & $\begin{array}{c}\text { Lymph } \\
255 \\
(98.43) \\
\end{array}$ & 0.00 & 6.49 & 39.0 & 8,450 & 11.86 \\
\hline 2. & $\begin{array}{l}\text { *Pyogenic } \\
(n=31)\end{array}$ & 0.00 & 5.9 & 0.00 & $\begin{array}{c}26 \\
(83.9)\end{array}$ & $\begin{array}{c}\text { Poly } \\
26 \\
(82)\end{array}$ & 0.00 & 7.7 & 31.6 & 13,750 & 10.9 \\
\hline 3. & $\begin{array}{c}\text { *Malignant } \\
(\mathrm{n}=49)\end{array}$ & 0.00 & 5.0 & 0.00 & 0.00 & $\begin{array}{l}\text { Lymph } \\
42 \\
(85.71)\end{array}$ & $\begin{array}{c}38 \\
(77.55)\end{array}$ & 7.2 & 69 & 10,220 & 8.2 \\
\hline
\end{tabular}

*Percentages are calculated independently for each etiology.

PE-Pleural effusion; n-Number of patients; +ve-Positive; AFB-Acid-fast Bacilli; ESR-Erythrocyte sedimentation rate; TLCTotal leukocyte count; Hb-Hemoglobin; Infl cells- Inflammatory cells; Poly-Polymorphonuclear leukocytes/neutrophils; Lymph-Lymphocytes

\begin{tabular}{|c|c|c|c|c|c|}
\hline \multicolumn{6}{|c|}{ Table II: Frequency distribution of sonographic patterns in different types of pleural effusions $(n=339)$} \\
\hline \multirow[b]{2}{*}{ S No. } & \multirow[b]{2}{*}{$\begin{array}{c}\text { Sonographic Patterns of } \\
\text { PE }\end{array}$} & \multicolumn{3}{|c|}{ Types of pleural effusions $\mathbf{n}(\%)$} & \multirow[b]{2}{*}{$\begin{array}{c}\text { Total Cases } \\
\text { n (\%) }\end{array}$} \\
\hline & & $\begin{array}{c}\text { Tuberculous } \\
(n=259)\end{array}$ & $\begin{array}{c}\text { Malignant } \\
(n=49)\end{array}$ & $\begin{array}{l}\text { Para-pneumonic } \\
\quad(n=31)\end{array}$ & \\
\hline 1. & Anechoic & $23(8.88)$ & $5(10.20)$ & $2(6.45)$ & $30(8.84)$ \\
\hline 2. & Complex septated & $187(72.2)$ & $03(6.12)$ & $6(19.35)$ & $196(57.81)$ \\
\hline 3. & Complex non-septated & 49 (18.91) & 39 (79.59) & $7(22.58)$ & $95(28.02)$ \\
\hline 4. & Homogenously echogenic & 0.00 & $2(4.08)$ & $16(51.61)$ & $18(5.3)$ \\
\hline
\end{tabular}

The details of pleural fluid analysis and laboratory investigations for tuberculous, pyogenic and malignant pleural effusions are shown in Table I.

On cytology, 308/339 (90.85\%) showed lymphocytic infiltration, $31 / 339 \quad(9.14 \%)$ neutrophilic infiltration and 38/339 (11.20\%) were found with malignant cells. About $76.4 \%$ cases with lymphocytic infiltration were of tuberculous etiology and $14.45 \%$ were found in malignant cases. Table II shows the distribution of sonographic patterns in different types of pleural effusions. There were 278 cases of complex pleural effusions, 190 patients with complex septated PE and 88 cases with complex non-septated PE. All these cases had a TB and malignant etiology. By considering complex septated pattern as predictor of TB diagnosis, 187 cases were TP, 3 cases were 
$\mathrm{FP}, 39$ cases were TN and 49 cases were $\mathrm{FN}$. Statistical analysis revealed a sensitivity of $79.24 \%$ (95\% confidence interval $73.5 \%$ to $84.23 \%$ ), specificity of $92.86 \%$ ( $95 \% \mathrm{Cl} 80.52 \%$ to $98.5 \%$ ), PPV of $98.42 \%(95 \% \mathrm{Cl} 95.44 \%$ to $99.46 \%)$, NPV of $44.32 \%(95 \% \mathrm{Cl} 37.96 \%$ to $50.87 \%)$, diagnostic accuracy of $81.29 \%$ (95\% Cl $76.21 \%$ to $85.70 \%$ ) and Positive Likelihood Ratio of 11.09 (95\% Cl 3.72 to 33.07). Similarly, sensitivity, specificity, PPV, NPV, positive likelihood ratio and diagnostic accuracy were also determined for malignancy by using sonographic septations. Comparative efficacy is depicted in Table III. By using sensitivity and specificity for TB and malignancy from Table III, the Fisher exact test $P$-value is 0.0418 which is statistically significant.

\begin{tabular}{|l|c|c|}
\hline \multicolumn{3}{|c|}{$\begin{array}{c}\text { Table III: Comparative Efficacy of Sonographic } \\
\text { Septations in TB and Malignant PE }\end{array}$} \\
\hline Statistical Test & $\begin{array}{c}\text { Tuberculous PE } \\
\mathbf{n = 2 3 6}\end{array}$ & $\begin{array}{c}\text { Malignant PE } \\
\mathbf{n}=\mathbf{4 2}\end{array}$ \\
\hline Sensitivity & $79.23 \%$ & $7.14 \%$ \\
\hline Specificity & $92.85 \%$ & $20.76 \%$ \\
\hline PPV & $98.42 \%$ & $1.57 \%$ \\
\hline NPV & $44.31 \%$ & $55.68 \%$ \\
\hline $\begin{array}{l}\text { Positive likelihood } \\
\text { ratio }\end{array}$ & 11.15 & 0.089 \\
\hline $\begin{array}{l}\text { Diagnostic } \\
\text { Accuracy }\end{array}$ & $81.29 \%$ & $18.70 \%$ \\
\hline
\end{tabular}

PPV: Positive predictive value, NPV: Negative predictive value.

*By using sensitivity and specificity for TB and malignant $P E, p$-value (by Fisher exact test) is 0.0418 which is statistically significant.

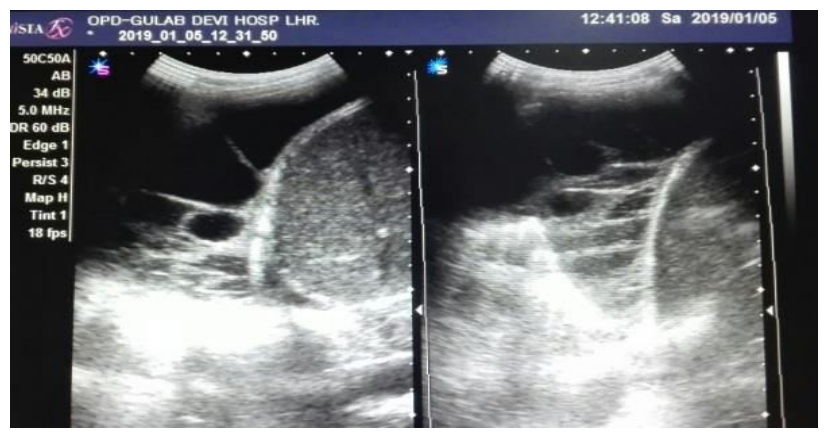

Figure 1: Transthoracic ultrasound image showing sonographic septations in Tuberculosis PE.

\section{Discussion}

We aimed to evaluate the usefulness of sonographic septations for the diagnosis of TB PE and its comparative efficacy in differentiating $T B$ from malignant PE. Exudative lymphocytic pleural effusions are a diagnostic dilemma and TB is a common cause in high prevalence areas. That is why many undiagnosed patients with exudative lymphocytic pleural effusions are found on anti-TB drugs. ${ }^{20}$ Pyogenic infections and malignancy are also significant contributors to this type. ${ }^{21}$ Sonographic septations are found in all these entities (TB, pyogenic and malignant) but with different frequencies.

This study showed a male to female ratio of 2.19:1, indicating a male predominance in our population. The mean age for our study population was 48.5 years with an inter-quartile range of 40 , which is higher than that reported by Hira et al. (48.5 vs 31.7 years). ${ }^{8}$ The mean age for non-malignant group was 28 years. This group included pyogenic infections and mostly fresh cases of tuberculosis. The mean age for malignant group was 41 years. A small number of TB cases were also found in elderly age group, which comprised mostly of previously treated patients. These cases were either due to reinfection or reactivation of previously healed lesions, as shown by other authors as well. ${ }^{22}$

Chest pain, fever and cough were the predominant symptoms in this study, which are the usual, nonspecific respiratory complaints. Dyspnea, expectoration and loss of appetite were also found in a significant number. These clinical features are consistent with the reports of Light ${ }^{2}$ and Porcel et al. $^{3}$ The sudden onset pointed towards pyogenic infection, clubbing of finger suggested chronic suppurative processes like pyothorax and pyopneumothorax and positive history of contact with TB-patients raised a high index of suspicion for tuberculosis. 
Maskell and Butland also reported tuberculous effusions as a predominant cause, followed by malignant and parapneumonic effusions. ${ }^{23}$ This high percentage for TB is due to the fact that our region is endemic for tuberculosis with Pakistan ranked as fifth among the high burden countries with an annual incidence of 497/100000. ${ }^{24}$ In short, tuberculosis is the commonest etiology, followed by malignancy and pyogenic infections (parapneumonic PE and empyema) which is compatible with reports from the current literature. $^{25}$

In this study, out of 339 cases, 196 had septations and $6 / 196$ pyogenic cases were isolated easily by acute onset, high blood and pleural fluid TLC count, culture sensitivity findings and homogenous echogenic pattern. Out of remaining 190 cases with septations, 3/190 (1.57\%) were malignant while 187/190 (98.42\%) had TB pleural effusion. Current researchers have tried the application of intrapleural sonographic septations for early diagnosis of tuberculosis in exudative lymphocytic pleural effusions. $^{26}$ The intra-pleural fibrinous matrix formation is due to disordered fibrin turn-over. The dynamic equilibrium is lost and fibrin formation is up-regulated while fibrin dissolution is downregulated. Furthermore, cytokines, such as TGF- $\beta$ and TNF- $\alpha$ enhance the fibrin matrix formation. According to Kunter et al., high levels of pleural fluid glucose, alpha-1 acid glycoprotein (AAG) and C-Reactive protein, seen in these patients might be responsible for pleural thickening. ${ }^{27}$

Philip-Joet et al. and Hua et al. displayed significantly higher levels of plasminogen activator inhibitor and Von Willebrand factor in patients with tuberculosis than in those with cancer. They also reported increased levels of tissue-type plasminogen activators in some malignant pleural effusions. These findings reveal that fibrinolytic activity is higher in malignant pleural effusions than tuberculous pleural effusions. ${ }^{28,29}$ Chen et al. also reported that complex septated pattern is a useful diagnostic tool for discriminating tuberculosis from lung cancer. ${ }^{26} \mathrm{~A}$ number of authors reported pleural infections, including tuberculosis as a cause of intra-pleural fibrosis, in addition to other causes. In 1989 Martinez et al. reported that winding bands were seen by ultrasonography in $38 \%$ patients with TB pleural effusion. ${ }^{30}$ These facts further confirm our findings that fibrin strands were more common in tuberculous than cancer-related pleural effusions, hence septations are more commonly encountered in tuberculous pleural effusions.

There were 190 cases of sonographic septations after excluding pyogenic cases (proven TB PE $n=187$; Malignant $P E n=3$ ) The frequency of TB effusion was $98.42 \%$ and that of malignancy was $1.57 \%$ with a wide gap between the two entities. The Fisher exact test was highly significant $(P<$ 0.00001 ) and suggests that tuberculosis can be predicted with a high degree of confidence in complex, exudative lymphocytic PE just by finding sonographic septations, with no need for any invasive procedure. By group wise analysis, there were 3 cases of septated pleural effusions in 49 cases of malignancy, which is only $6.1 \%$ of total malignant group, indicating a very low chance of malignancy in septated pleural effusions. Similarly, there were 187 cases (79.23\%) of septated pleural effusions out of 236 complex TB-pleural effusions, indicating that by finding sonographic septations, chance of malignancy is only $6.1 \%$, while for tuberculosis it is $79.23 \%$. It means we can correlate sonographic septations with tuberculosis by high level of confidence in clinical suspects.

Conventionally, the differentiation between TB and malignant pleural effusion is made by pleural fluid cytology, pleural biopsy, histopathology and immuno-cytology, which are invasive, costly, timeconsuming and expertise-dependant procedures. Furthermore, the availability of these facilities is also an issue in resource limited populations. On 
the other hand, sonographic septations do not have such disadvantages and can help in predicting tuberculosis immediately, without any delay, invasion and complication.

In the light of this discussion, it can be said that the finding of sonographic septations is useful in clinical practice for differentiating tuberculous from malignant pleural effusions with confidence, in high prevalence populations. It can be very useful in those areas where facilities for invasive procedures are not available or in patients who are not fit for invasive procedures.

The main limitation of our study was that this was a single centre study and the number of patients in malignant and pyogenic group was small as compared to TB group. This might be because the study is prevalence dependent. As 339 consecutive patients were included in the study, there is more probability of getting TB cases in larger number in an endemic population as compared to non-TB patients.

\section{Conclusion}

Sonographic septations are non-invasive, easily detectable, cost effective and valuable predictor of TB diagnosis in exudative lymphocytic pleural effusions, in high prevalence populations. It can be used with confidence for making differentiation between malignant and TB PEs. Furthermore, it can provide tremendous help for point of care diagnosis in non-ambulatory and serious patients.

\section{Acknowledgement}

The authors are thankful to Mr. Mehfooz Ahmed and Mr. Tahir for their valuable cooperation during the study.

\section{References}

1. Global tuberculosis report 2015. Geneva: World Health Organization, 2015. Available online: http://apps.who.int/iris/bitstream/10665/191102/1 /9789241565059_eng.pdf?ua=1, accessed 18 April 2016.

2. Light RW. Update on tuberculous pleural effusion. Respir ology. 2010; 15(3): 451-8. Doi: 10.1111/j.1440-1843.2010.01723.x.

3. Porcel JM, Esquerda A, Vives M, Bielsa S. Etiology of pleural effusions: analysis of more than 3,000 consecutive thoracenteses. Arch Bronconeumol. 2014; 50(5): 161-5. Doi: 10.1016/j.arbres.2013.11.007.

4. Rauniyar S, Agarwal A, Bhattacharya S. Comparison 1 of needle biopsy with pleural fluid analysis for the evaluation of pleural lesions. Nepal Med Coll J. 2004; 6(2): 112-5. PMID: 16295740

5. Liam CK, Lim KH, Wong CMM. Causes of pleural exudates in a region with a high incidence of tuberculosis. Respirology. 2001; 5 (1): 33-38. Doi: 10.1046/j.1440-1843.2000.00223.x

6. Avnon L, Kalchiem-Dekel O, Gozlan-Talmor A, Shimonovitch F, Shalev R, Maimon N. The Role of Closed Pleural Biopsy in the Diagnosis of Tuberculous Pleurisy in a Population At-Risk. Harefuah. 2016; 155(2):110-4. PMID: 27215124

7. Dixon G,Fonseka D,Maskell N. Pleural controversies: image guided biopsy vs. thoracoscopy for undiagnosed pleural effusions. J Thorac Dis. 2015; 7(6): 1041-1051. Doi: 10.3978/j.issn.20721439.2015.01.36

8. Hira H, Ranjan R. Role of percutaneous closed needle pleural biopsy among patients of undiagnosed exudative pleural effusion. Lung India. 2011; 28(2): 101-4. Doi: 10.4103/0970-2113.80319

9. Zarić B, Kuruc $V$, Milovančev A, Markovic $M$, Šarčev $T$, Čanak $V$, et al. Differential diagnosis of tuberculous and malignant pleural effusions: what is the role of adenosine deaminase? Lung. 2008; 186(4): 233-240. Doi: 10.1007/s00408-008-9085-7.

10. Beckh S, Bo PL, Lessnau K-D. Real-time chest ultrasonography: a comprehensive review for the pulmonologist. Chest. 2002; 122(5): 1759-73. Doi: 10.1378/chest.122.5.1759.

11. Chian CF, Su WL, Soh LH, Yan HC, Perng WC, Wu CP. Echogenic swirling pattern as a predictor of malignant pleural effusions in patients with malignancies. Chest. 2004; 126(1): 129-34. Doi: 10.1378/chest.126.1.129

12. Brogi E, Gargani L, Bignami E, Barbariol F, Marra A, Forfori $\mathrm{F}$, et al. Thoracic ultrasound for pleural effusion in the intensive care unit: a narrative 
review from diagnosis to treatment. Crit Care. 2017; 21(1): 325. Doi:10.1186/s13054-017-1897-5

13. Bedawi EO, Hassan M, Harriss E, McCracken D, Asciak R, Mercer R, et al. S57 Sonographic septations in pleural infection-what do they actually mean? Thorax. 2018; 73(4): A35.

14. Hassan Wafaa A, Alkarn Atef F, Kamel M. Can chest ultrasonography differentiate between benign and malignant effusions? Egypt J Bronchol. 2015; 9(2): 165-9. Doi: 10.4103/1687-8426.158061

15. Vorster MJ, Allwood BW, Diacon AH, Koegelenberg CF. Tuberculous pleural effusions: advances and controversies. J Thorac Dis. 2015; 7(6): 981-91. Doi:10.3978/j.issn.2072-1439.2015.02.18

16. Aggarwal AN, Agarwal $R$, Sehgal IS, Dhooria $S$. Adenosine deaminase for diagnosis of tuberculous pleural effusion: A systematic review and metaanalysis. PLoS One. 2019; 14(3): e0213728. Doi:10.1371/journal.pone.0213728

17. Zhai K, Lu Y, Shi HZ. Tuberculous pleural effusion. J Thorac Dis. 2016; 8(7): E486-E494. Doi: 10.21037/jtd.2016.05.87

18. Zhou X, Jiang $P$, Huan X, Li W, Chen $Y$, Gao H, et al. Ultrasound-Guided versus Thoracoscopic Pleural Biopsy for Diagnosing Tuberculous Pleurisy Following Inconclusive Thoracentesis: A Randomized, Controlled Trial. Med Sci Monit. 2018; 24: 7238-48. Doi:10.12659/MSM.912506

19. Mohamed AS, Abo-Sheisha DM, Shamloula MM. Exudative pleural effusions: Comparative study of image assisted Abram needle pleural biopsy and medical thoracoscopy. Egypt J Chest Dis Tuberc. 2014; 63(3): 625-8. Doi: 10.1016/j.ejcdt.2014.02.014

20. Light RW. Pleural diseases. 6th ed. Philadelphia: Lippincott Williams \& Wilkins, 2013.Mayse ML. Nonmalignant pleural effusions. In: Fishman AP, editor. Fishman's Pulmonary Diseases and Disorders. New York: McGraw-Hill; pp. 1487-504.

21. Valdes L, Alvarez D, San Jose E, Penela P, Valle JM, García-Pazos JM, et al. Tuberculous pleurisy: a study of 254 patients. Arch Intern Med. 1998; 158(18): 2017-21. Doi: 10.1001/archinte.158.18.2017

22. Emad A, Rezaian G. Diagnostic value of closed percutaneous pleural biopsy vs pleuroscopy in 20 suspected malignant pleural effusion or tuberculous pleurisy in a region with a high incidence of tuberculosis: a comparative, age-dependent study. Respir Med. 1998; 92(3): 488-92. Doi: 10.1016/s0954-6111(98)90296-7

23. Maskell N, Butland R. BTS guidelines for the investigation of a unilateral pleural effusion in adults. Thorax. 2003; 58(Suppl 2): ii8-17. Doi: 10.1136/thorax.58.suppl_2.ii8

24. Fatima R, Harris R, Enarson D, Hinderaker S, Qadeer $E$, Ali K, et al. Estimating tuberculosis burden and case detection in Pakistan. Int J Tuberc Lung Dis. 2014; 18(1): 55-60. Doi: 10.5588/ijtld.13.0198

25. Hallifax RJ, Corcoran JP, Ahmed A, Nagendran M, Rostom $\mathrm{H}$, Hassan $\mathrm{N}$, et al. Physician-based ultrasound-guided biopsy for diagnosing pleural disease. Chest. 2014; 146(4):1001-06. Doi: 10.1378/chest.14-0299

26. Chen HJ, Hsu WH, Tu CY, Yu YH, Chiu KL, Hang LW et al. Sonographic septation in lymphocyte-rich exudative pleural effusions: a useful diagnostic predictor for tuberculosis. J Ultrasound Med. 2006; 25(7): 857-63. Doi: 10.7863/jum.2006.25.7.857

27. Kunter E, Ilvan A, Kilic E, Cerrahoglu K, Isitmangil T, Capraz $F$, et al. The effect of pleural fluid content on the development of pleural thickness. Int J Tuberc Lung Dis. 2002; 6(6): 516-22. doi: 10.5588/09640569513039.

28. Philip-Joet F, Alessi $M$, Philip-Joet C, Aillaud $M$, Arnaud A, Juhan-Vague I. Fibrinolytic and inflammatory processes in pleural effusions. Eur Respir J. 1995; 8(8): 1352-6. Doi: 10.1183/09031936.95.08081352

29. Hua CC, Chang LC, Chen YC, Chang SC. Proinflammatory cytokines and fibrinolytic enzymes in tuberculous and malignant pleural effusions. Chest. 1999; 116(5): 1292-6. Doi: 10.1378/chest.116.5.1292

30. Martínez OC, Serrano BV, Rodr Romero Rí. Real-time ultrasound evaluation of tuberculous pleural effusions. J Clin Ultrasound. 1989; 17(6): 407-10. Doi: 10.1002/jcu.1870170605 